\title{
SIGNIFICAÇÕES DE JOGO: um estudo com professores de Educação Física
}

\author{
Marilia Freire' \\ Ana Mercês Bahia Bock²
}

\section{RESUMO}

Este trabalho investigou as significações de jogo constituídas pelos professores de Educação Física que atuam nas primeiras séries do ensino fundamental. Utilizou-se a entrevista semiestruturada para analisar: a função do trabalho com o jogo; as significações procedentes de professores de outras áreas e da equipe gestora sobre o trabalho com o jogo e; as condições de trabalho com o jogo. Os resultados revelaram: a tensão entre o competir/cooperar, a desvalorização do futebol e a busca pela ressignificação; a valorização sobre a necessidade de trabalhar a leitura e a escrita, as capacidades físicas e o futebol; sendo que os maiores incômodos encontram-se centrados no objetivo a ser alcançado e no "como", ao invés de "por quê". Concluiu-se que o trabalho com o jogo vive um processo de busca de valorização e ressignificação da sua função, o que reitera a necessidade desse olhar historicizado para o sujeito que constitui a Educação Física escolar.

Palavras-chave: Educação Física Escolar. Jogo. Significações.

1 Doutora em Educação. Professora da Universidade Estadual da Bahia (UNEB). Guanambi/Bahia, Brasil.

E-mail: mariliafr@terra.com.br

2 Doutora em Psicologia Social. Professora da Pontifícia Universidade Católica de São Paulo (PUC). São Paulo/ São Paulo, Brasil. E-mail: anabbock@gmail.com 


\title{
MEANINGS OF PLAY: a study with school-level Physical Education teachers
}

\begin{abstract}
This paper investigated the meanings imbued by Physical Education teachers upon play activities with their students from the first primary education classes. We have employed semi-structured interview in order to analyze: the function of play within their work; the meanings coming from teachers of other disciplines and the administrative team about this work with play; and the conditions of the work with play. The results revealed: a tension between competing and cooperating, the devaluing of soccer and a search to re-signification; the valuing of the need to work on reading and writing; physical abilities and soccer; and the central issues are around the final goal of play and the "how" instead of "why". We have reached the conclusion that work with play is going through a process of search for value and re-signification of its function, which reiterates the need for this historical approach for the subject that constitutes schoollevel Physical Education.
\end{abstract}

Keywords: School-Level Physical Education. Play. Meanings.

SIGNIFICACIONES DEL JUEGO: un estudio con profesores escolares de Educación Física

\section{RESUMEN}

Este trabajo investigó las significaciones de juego constituidas por los profesores de Educación Física actuantes en los primeros grados de la escuela primaria. Se utilizaron entrevistas semiestructuradas para analizar: la función del trabajo con juegos; los significados provenientes de profesores de otras áreas y el equipo de gestión sobre el trabajo con juegos y; las condiciones de trabajo con juegos. Los resultados revelaron: la tensión entre competir/cooperar, la desvalorización del fútbol y la búsqueda de su resignificación; la valorización de la necesidad de trabajar con lecto-escritura, las capacidades físicas y el fútbol; siendo que las mayores dificultades se encuentran alrededor del objetivo a alcanzar y en el "cómo", en vez del "por qué". Se concluyó que el trabajo con juegos pasa por un proceso de búsqueda de una valorización y resignificación de su función, lo que reitera la necesidad de esta mirada histórica del sujeto constituido por la Educación Física escolar.

Palabras clave: Educación Física Escolar. Juego. Significaciones. 


\section{INTRODUÇÃO}

Partimos de alguns estudos sobre as concepções de jogo presentes na prática pedagógica da Educação Física (MUNIZ; FONSECA, 2000; STUMP, 2000; SANTOS, 2004; LÜDORF, 2005; FIGUEIREDO et al., 2008), com a hipótese de que são concepções que funcionalizam o jogo, deixando de percebê-lo como produto da cultura e como atividade que contém e reproduz as significações e valores sociais. Tal hipótese é sustentada pelos argumentos de Neira (2009). O autor ao analisar a literatura da Educação Física escolar enfatiza que tanto nos textos mais antigos quanto nos textos mais recentes predomina a visão funcionalista de jogo. Nos textos mais antigos enfatizam o jogo como finalidade moral, como ocupação do tempo livre ou como caráter regulador do comportamento das crianças. Já nos textos mais recentes caracterizam o jogo como desenvolvimento cognitivo, afetivo e social ou quando muito o caracterizam como possibilidade de desenvolvimento das habilidades culturalmente determinadas, sem compreender quais são e porque são.

A partir daí, interessou-nos as significações de jogo constituídas pelos professores de Educação Física, entendendo que têm implicações na prática do trabalho desses profissionais. Assim, delimitamos nosso problema de pesquisa a um estudo da dimensão subjetiva do trabalho com o jogo na Educação Física.

Dimensão subjetiva é um construto teórico que tem sido utilizado por Gonçalves e Bock (2009) para fazer referência à presença da subjetividade como aspecto ou característica da realidade objetiva. As autoras partem do pressuposto que a subjetividade não existe somente no âmbito individual, mas existe também no âmbito das relações sociais, como uma subjetividade coletiva.

A dimensão subjetiva pode ser identificada a partir de aspectos psicológicos já conhecidos e reconhecidos por outras teorizações e se referem à forma como os sujeitos registram o mundo que os cerca e no qual atuam e se relacionam. São sentimentos, ideias, valores, imagens, pensamentos, registro de memória, planos de ação, enfim são aspectos psicológicos que estão no âmbito do sujeito e para além dele, no âmbito das relações sociais e da produção coletiva.

Desta perspectiva, todos os fenômenos culturais e sociais existentes a partir da presença e produção dos sujeitos possuem uma dimensão que é do sujeito que o constitui. É esta a dimensão subjetiva dos fenômenos sociais.

A subjetividade deixa de ser um aspecto que se contrapõe à objetividade; deixa de ser o interno em oposição ao externo que é coletivo, para constituir-se como uma nova possibilidade de leitura do mundo.

No nosso caso, para compreendermos a dimensão subjetiva da Educação Física escolar para as séries iniciais do ensino fundamental, escolhemos o jogo como elemento de análise.

Assim, do ponto de vista teórico-conceitual, nosso trabalho se orientou pela superação da concepção funcionalista de jogo presente na maior parte das produções científicas sobre o tema. Ou seja, criticamos a compreensão de jogo na Educação Física escolar pautada na significação exclusivamente instrumental - como recurso pedagógico, desconsiderando-se seu papel enquanto manifestação cultural. 


\section{OBJETIVO}

Investigar as significações de jogo constituídas pelos professores de Educação Física que atuam nas primeiras séries do ensino fundamental ${ }^{3}$ de uma diretoria de ensino da rede estadual paulista, localizada no interior do estado de São Paulo.

\section{METODOLOGIA}

O referencial teórico-metodológico deste trabalho é pautado na perspectiva da psicologia sócio-histórica, fundamentado por autores contemporâneos da área da psicologia da educação como Aguiar e Ozella (2006), Bock (1999), Gonçalves e Bock (2009) e Rey (2005 e 2009).

Como fontes, privilegiamos as informações obtidas por meio de questionários e entrevistas semiestruturadas. O questionário foi dividido em duas partes: a primeira, destinada à caracterização e identificação dos professores; descrição em relação ao tempo de atuação na Educação Física escolar, na rede estadual e na escola que atuavam no ano em que a pesquisa foi realizada; atuação em outro segmento da EF; formação acadêmica, instituição e ano de conclusão; séries em que atuavam no ano em que a pesquisa foi realizada; carga horária e motivo da escolha pela EF/área. A segunda parte, contendo três perguntas abertas e duas fechadas, destinada ao conhecimento da definição de jogo; das dificuldades encontradas no trabalho com o jogo; do principal objetivo no trabalho com o jogo, e, ainda, se o professor trabalhava com o jogo em suas aulas e se o professor se dispunha a participar, posteriormente, de uma entrevista de aprofundamento.

Dentre um total de 52 professores que responderam o questionário, pudemos contar com a participação de 25 sujeitos que se dispuseram a participar da segunda etapa da pesquisa, sendo selecionados quatro professores, dentre eles, para realizar a entrevista semiestruturada.

A escolha desses quatro professores foi feita a partir do tipo de resposta dada no questionário e da disponibilidade dos professores em participar da segunda etapa; manifestação de vontade expressa ao final do questionário. O conjunto de sujeitos apresentou uma diversidade de palavras para designar o jogo, as quais dizem respeito à natureza do jogo, aos elementos que caracterizam e compõem o jogo, à finalidade, aos processos ou habilidades que o compõem. Algumas respostas continham aspectos variados e outras com poucos aspectos.

Portanto, a partir da categorização dos dados, escolhemos dois dentre os sujeitos que continham na sua resposta uma diversidade muito grande de aspectos. Escolhemos mais dois que definiram o jogo de forma imprecisa, minoritária e com poucos e impreci-

3 No ano em que a pesquisa foi realizada, o ensino fundamental passava por um período de reformulação quanto à organização e à nomenclatura das suas séries, buscando adequar-se a legislação vigente, no que se refere ao ensino fundamental de 9 anos. Portanto, as primeiras séries do ensino fundamental que constituía o ensino fundamental I, corresponderia, em breve, aos primeiros anos do ensino fundamental de 9 anos. 
sos aspectos. Portanto, entrevistamos quatro sujeitos. Ainda procuramos escolher dentre os sujeitos dois homens e duas mulheres, dentre os 25 que se dispuseram a participar da entrevista, na qual procuramos explorar e aprofundar os dados do questionário.

Elaboramos um roteiro de entrevista específico para cada professor, buscando aprofundar as respostas dadas no questionário. Apesar de o roteiro de entrevista ter sido elaborado de acordo com as respostas dadas no questionário, procuramos explorar aspectos comuns e importantes de serem aprofundados, na concepção de cada professor, tais como: o adversário num jogo competitivo e num jogo cooperativo; a construção das regras; o coletivo; a função do trabalho com o jogo; como as pessoas encaram seu trabalho com o jogo; as condições (dificuldades) de trabalho com o jogo.

As entrevistas de aprofundamento tinham como objetivo buscar informações complementares acerca do sentido subjetivo sobre o jogo, isto é, captar o valor que jogo tem para estes professores. Segundo González Rey (2005, p. 111), "Os sujeitos individuais selecionados serão uma via essencial para o aprofundamento das informações implicadas no desenvolvimento do modelo teórico em construção".

Para análise dos dados obtidos por meio das entrevistas semiestruturadas foram seguidos os procedimentos dos "Núcleos de Significação" da forma como nos propõem Aguiar e Ozella (2006), que são formas dialogantes de produzir informações, a partir da imersão dos dados. Esta forma de análise nos permitiu analisar os motivos que impulsionam o professor a utilizar o jogo, o valor dado a ele e o objetivo a ser alcançado, além de embasar a forma como ele trabalha com o jogo em suas aulas.

Considerar a linguagem como instrumento de comunicação e organizadora do pensamento é o elemento fundamental, neste tipo de análise, para compreendermos as ações do sujeito e para podermos nos aproximar da compreensão da subjetividade, uma vez que a linguagem contém os sentidos que são carregados de significações coletivas, as quais buscamos conhecer.

Os "Núcleos de Significação" propostos por Aguiar e Ozella (2006) nos permitem destacar e analisar, na fala dos sujeitos, as palavras com significados dentro do contexto social no qual estão inseridas, aproximando-nos da zona de sentidos, revelando o pensamento do sujeito.

Assim, transcrevemos a entrevista na íntegra e realizamos várias leituras flutuantes da fala obtida por meio dela, com o objetivo de nos familiarizarmos com o material. Em seguida, destacamos (sublinhamos) frases ou trechos da fala do sujeito que indicavam certa frequência, seja por sua repetição ou pela reiteração, possibilitando a construção dos Indicadores.

Os Indicadores são construídos com as frases ou trechos da fala do sujeito. Como as frases ou trechos da fala do sujeito reúnem uma grande diversidade, Aguiar e Ozella (2006) propõem aglutiná-los por temática (eixos temáticos), em quadros, seja por similaridade ou semelhança, seja por complementaridade ou contraposição.

Após a construção do quadro com os Indicadores, passamos para o próximo passo, denominado de construção dos Núcleos de Significação. Os autores recomendam que se faça mais uma releitura do material, seguindo o mesmo critério de similaridade 
e contraposição, aproveitando para selecionar trechos dos discursos que possam dar nomes aos núcleos. Após a construção dos núcleos de significação realizamos uma síntese interpretativa de cada sujeito.

Seguimos o mesmo procedimento de análise para cada um dos quatro sujeitos.

Diante da construção dos Núcleos de Significação de cada sujeito, destacamos três categorias constitutivas acerca das significações do jogo pelos professores de Educação Física: a função do trabalho com o jogo; as significações procedentes de professores de outras áreas e da equipe gestora sobre o trabalho com o jogo e; as condições de trabalho com o jogo. Neste trabalho nos propomos a apresentar os resultados obtidos por meio da entrevista semiestruturada realizada com os quatro professores de Educação Física: Júlio Cesar, Isabel, Augusto e Joana, cujos nomes são fictícios, conforme discutimos a seguir.

\section{RESULTADOS E DISCUSSÃO}

\section{A função do trabalho com o jogo}

Ao analisarmos as respostas, notamos que a função do trabalho com o jogo encontra-se diante da tensão de cooperar/competir. O professor Júlio César trabalha com o jogo cooperativo e competitivo e afirma que o jogo "[...] vai preparando para a vida. Tem situações que eu faço com que a criança saia, tem situações que eu deixo as crianças mais". Isabel também trabalha com o jogo cooperativo e competitivo para que os alunos aprendam que "[...] na vida a gente ganha que na vida a gente perde". Além disso, ela trabalha com o jogo pré-desportivo como uma preparação para outro jogo (esporte). O professor Augusto trabalha com o jogo semicooperativo (cita como exemplos, o Korfball que mistura elementos do basquete e do handebol, o Tchoukball que elementos do voleibol e do handebol), no qual cooperar e competir estão juntos numa única atividade. Alega que a socialização acontece quando ele ensina para o aluno que "[...] nessa vida nem tudo é só competir, ele tem que cooperar". Joana não vê "nenhuma maldade" ou "coisa ruim" no jogo competitivo, pois tanto no jogo cooperativo como competitivo "[...] o adversário é o que vai fazer você analisar a tática, o adversário ajuda você a ser melhor". Acrescenta ainda que o esporte "[...] com regras universais e bem delimitado, as chances de ter o fracasso e perder são maiores". Além disso, também trabalha com o jogo pré-desportivo como antecessor ao esporte, "inventa" formas de jogar, no sentido de estimular a criatividade dos alunos.

Os professores entrevistados destacam a importância do jogo cooperativo e do jogo competitivo para se trabalhar a autonomia, o autoconhecimento, o autoquestionamento, a autocrítica e a autoestima, a inclusão e a exclusão, o respeito pelas regras - o certo e o errado, o saber ganhar e o saber perder e; a questão de gênero, como se fossem comportamentos pessoais unicamente dependentes do homem e da sua relação consigo mesmo, sem problematizar os motivos pelos quais as regras do jogo são do jeito que são e como poderiam mudá-las, sem tentar entender as razões e as contradições desses tipos 
de comportamentos presentes no jogo e na sociedade. No que concerne ao trabalho com o futebol, ressaltamos o sentimento de desvalorização dos professores entrevistados ao ter como função de seu trabalho o futebol. Júlio Cesar permite que os alunos (os meninos) joguem futebol "[...] final de mês, numa aula liberada para eles [...]" ou "na hora do recreio" momento em que "organizam um ranking das salas". Porém, ressalta que trabalha com o futebol americano como uma variação do futebol, mudando as regras no sentido de evitar o contato-físico, da mesma forma que trabalha com o Flagball e, o Dodge Ball, variação da queimada. Júlio Cesar valoriza em suas aulas a cultura corporal dos Estados Unidos e compara os alunos da escola pública estadual com os alunos das escola particular ao justificar que as crianças da rede particular têm uma cultural maior e melhor que os alunos da escola pública "[...] por terem uma condição social melhor tem um acesso a uma cultura melhor que os nossos alunos da escola pública".

Isabel só permite que o futebol seja jogado em suas aulas se for num esquema de "troca", três aulas "normais" de fundamentos de qualquer esporte (exceto futebol) e uma aula de futebol. A professora enfatiza: "[...] uma vez por mês eu sento e meus alunos jogam bola (futebol)". Apesar de Isabel afirmar que "[...] a cultura do bairro, a cultura do Brasil é futebol[...]", ela não vê sentido em desenvolvê-lo em suas aulas e justifica: "futebol ele vai aprender na rua".

Augusto afirma "[...] eu não dou futebol, mas raramente, um dia lá ou outro eu dou [...]" em contrapartida propõe aos alunos: "[...] vamos fazer atividade que dão uma distanciada disso (do futebol) [...]", referindo-se a "pelada deles (dos alunos) ". Evidencia, também, que "o Brasil é o país do futebol", mas faz uma ressalva: "[...] um dia ele vai ser um país de todos os esportes, do badminton, do Korfball, do tchoukball".

Joana afirma "[...] eu comecei a dar aula aqui o ano passado. Ano passado aparecia o futebol. No final do ano não aparecia mais. Esse ano não apareceu mais". Contudo, apesar da professora compreender o jogo como "patrimônio cultural da humanidade" ela excluí essa manifestação cultural da sua prática pedagógica.

Em tese, o futebol é uma manifestação cultural presente na vivência dos alunos. Entretanto, é excluída da prática pedagógica dos professores de Educação Física entrevistados, atribuindo-lhe concepções deturpadas. Em substituição ao futebol, os professores desenvolvem jogos semicooperativos, pré-desportivos, futebol americano, Flagball, Korfball, Dodge Ball, Tchoukball, desprovidos de significado cultural.

É possível notar que os professores de Educação Física entrevistados consideram a presença do futebol nas primeiras séries do ensino fundamental como um incômodo, chegando a evitá-lo ou até mesmo a negá-lo; entretanto, ao mesmo tempo, responsabilizam a cultura (individual e educacional), o bairro, o Brasil, a mídia e a própria natureza humana pelas significações constituídas sobre o trabalho com o jogo na Educação Física escolar. Por deixar de trabalhar o futebol, perde-se a chance de abordar os significados socioculturais que estão presentes nesse esporte e de propiciar um estudo mais crítico e aprofundado acerca da sua origem histórica e desenvolvimento (CAPARROZ, 2007).

O fato é que os professores reconhecem o cooperar/competir como função do trabalho com o jogo na Educação Física escolar, entretanto, sentem-se desvalorizados pelo 
trabalho com o futebol e não têm intencionalidade pedagógica organizada e sistematizada para desenvolvê-lo de forma crítica e consciente, inclusive buscam sua ressignificação, com o desenvolvimento de jogos e atividades "inventadas", desviando do modo como essas manifestações culturais foram construídas historicamente.

Segundo Neira e Nunes (2008) estas propostas se aproximam de uma visão funcionalista da Educação Física. Tratam as práticas corporais de forma superficial e cumprem seu papel alienante, perdendo a chance de refletir sobre seu contexto histórico, social e político, o que significa jogar simplesmente por jogar. Nesse sentido, os aspectos relacionados às questões de etnia, classe social e gênero, entre outros, são obrigatoriamente ocultados.

Na perspectiva da psicologia sócio-histórica não existe prática pedagógica que seja neutra. De acordo com Vásquez (1968) nenhuma práxis, individual ou coletiva, é desprovida de um objetivo. Segundo o autor, não existe uma práxis cega, uma prática sem sujeito consciente, portanto, o sujeito está carregado de intenções e de qualquer forma ele realiza e objetiva suas intenções na sua prática. Assim, valores como: solidariedade, discriminação, racismo, preconceito de classes, questões de gênero e respeito, dentre outros essenciais à formação humana, são constituídos na e pela interação social. A forma como o professor intervém nesse processo é de fundamental importância para que os valores presentes no jogo sejam ressignificados e transformados.

\section{As significações procedentes de professores de outras áreas e da equipe gestora sobreo trabalho com o jogo}

Os professores entrevistados são afetados pelo que consideram ser a opinião dos professores de outras áreas, dos pais e da equipe gestora sobre seus trabalhos com o jogo. São significações procedentes de professores de outras áreas e da equipe gestora e que são expressas em frases ouvidas pelos professores entrevistados como: "Professor de Educação Física dá uma bola para os alunos jogarem e vai ler o jornal. ", "Educação Física é para eles praticarem esportes, para eles saírem e ela está dentro [da sala]. ", ou, ainda, "Essas crianças precisam de uma atividade de mais força, correr. "

No entanto, é interessante notar que apenas Isabel não reconhece que se sente desvalorizada com o entendimento do seu trabalho com o jogo pela coordenadora pedagógica, inclusive e também quando desenvolve trabalho com o jogo com a professora regente e de Arte, dentro da perspectiva da leitura e escrita, mesmo alegando a falta de entendimento do seu papel como professora de Educação Física escolar.

A minha coordenadora dá um tudo para melhorar o ensino com as professoras e comigo. A gente trabalha junto demais. A professora da sala de aula, eu e a professora de Arte. Então, ela fez um projeto. [...] Então, eu que faço a parte prática, a Marina (professora de Arte) faz o brinquedo e a professora e (...). Com o projeto 'Ler e Escrever' que tem muita música [...] então monta o projeto em cima da música, então, a gente sempre está trabalhando junto. Eu acho que esse trabalho, (...) da Educação Física, da proposta, também vai vir bem ali no projeto 'Ler e Escrever'. (Isabel) 
Eu acho que a maioria não tem muito conhecimento. Eu falo que lá na escola você pode fazer o que você quiser, que o povo não tem muito essa coisa de (...). A minha coordenadora ela entende bastante. A gente sempre conversa sobre o jogo. Ela e as professoras acham importantíssimo, também, essa parte para os alunos, para o desenvolvimento. Às vezes tem algum jogo lá no 'Ler e escrever' e eles pedem para que eu faça com alunos, para os alunos transcreverem as regras, para os alunos melhorarem a disciplina. [...] os pais da minha escola eles não são muito presentes. Às vezes um ou outro vem perguntar para mim o que eu faço na escola. (Isabel)

[...] ela chegou a semana passada e falou: Você terminou seu conteúdo? Falta alguma coisa? Então, ela é minha coordenadora pedagógica tem essas interferências, mas a minha diretora não. Nunca interferiu em nada. Nunca perguntou nada sobre a aula. (Isabel)

Joana desenvolve seu trabalho com o jogo se valendo dessa mesma perspectiva ao destacar que trabalha com os jogos do programa "Ler e Escrever" ${ }^{4}$, em que ela busca sua ressignificação, incorporando conhecimentos da Saúde Coletiva. Joana, assim como Isabel, não se sente desvalorizada, mas ressalta a influência da trajetória histórica da Educação Física na opinião da equipe gestora e dos professores de outras áreas sobre seu trabalho com o jogo.

[...] a maioria gosta, mas alguns têm uma visão de Educação Física, ainda muito biologizada, que é uma visão da sociedade, não é nem deles. Isso foi construído na sociedade. A Educação Física é sarada, você é forte, você aguenta. Eles acham assim: 'Nossa, mais essas crianças precisam de uma atividade de mais força, correr'. Isso em outra escola, em outras duas. Aqui, como já tem o limitador de espaço, eles pensam assim, mas verbalizam muito pouco, porque já sabem que o próprio espaço, também, seria um limitador de fazer tipo de atividade, tipo esportes competitivos. É isso! Uma visão biologizada ou de esportes competitivos para eles. (Joana)

Eu penso nas competências do 'Ler e Escrever'. O 'Ler e escrever' vem com jogos no final do livro e tem mais as parlendas, também que eu adoro fazer com $1^{\text {a }}$ e $2^{\text {a }}$ séries. A gente canta, bate palma, tem ritmo, emita índio, não emita e junta com a fantasia. Você desenha, coloca no seu corpo, então, você vai dançar e cada um vai ser um bicho. Eu penso nas competências, eu me aderi a isso. Eu juntei as competências que cabe na Educação Física para eu desenvolver, que são pertinentes ao currículo, junto com esses princípios que eu tenho de Saúde Coletiva. (Joana)

Já Júlio César mesmo reconhecendo a falta de formação direcionada para o real objeto de estudo da Educação Física, a prioridade dada à leitura e escrita nos cursos de formação em serviço e a necessidade de reafirmar que seu trabalho com o jogo não se restringe ao futebol, não se sente desvalorizado por isso.

4 Programa implementado pela Secretaria da Educação que considera a competência da leitura e da escrita como única linguagem e não tem uma proposta específica para a área de Educação Física. 


\begin{abstract}
Praticamente, não tem interferência. De uma certa forma a gente acaba ficando assim (...) não digo largado (...), mas assim, tanto a equipe gestora e os professores, assim, acabam não interferindo. Muitos professores acabam, assim, entrando, vibrando, percebendo a aula, porque a criançada chega lá super eufórica, comentando da aula. [...] Com a equipe gestora a exigência é mais em relação a documentação. Mas em relação a conteúdo a gente acaba ficando, de uma certa forma, desamparado. Tanto é que vários anos de HTPC ${ }^{5}$ aqui, eu aprendi as fases de escrita. Eu consegui identificar o que é uma fase alfabética, silábico com valor e sem valor. (Júlio César)
\end{abstract}

Eu já fui questionado em relação ao futebol. Ah, porque você não dá futebol? Meu filho joga futebol tão bem. Aí eu explico, porque eu tenho todo um conteúdo. Eu tenho uma gama enorme de atividades, futebol é apenas uma delas. Então, costumo trabalhar algumas épocas do ano só. (Júlio César)

Augusto trabalha com o jogo de forma a integrar diferentes áreas de conhecimento. Mostra-se tão seguro sobre sua função, alegando que é uma disciplina que os alunos mais gostam, que mesmo revelando sentimento de desvalorização quando ouve que professor de Educação Física "dá uma bola para os alunos jogarem e vai ler o jornal", nega que isso seja um fator de desvalorização da profissão, no entanto, busca sua ressignificação desenvolvendo seu trabalho com o jogo de forma "transversal".

[...] muito bom, porque eu troco muito, procuro trabalhar transversalmente falando. Então, dentro da minha disciplina, eu trabalho matemática, eu trabalho ciências, trabalho consciência, [...] o sensorial. Estão todos presentes no meu trabalho. Então, melhor impossível. (Augusto)

Notamos nas falas dos professores o sentimento de valorização/desvalorização do trabalho com o jogo no contexto da Educação Física escolar, quando os professores de outras áreas e a equipe gestora expressam opiniões sobre a necessidade de trabalhar a leitura e a escrita; as capacidades físicas e, principalmente, quando o futebol está presente nas aulas. Assim, foi possível notar que há mais que uma dicotomia entre a valorização e a desvalorização, existe uma contradição que demonstra que os professores reconhecem que há uma desvalorização, mas não assumem sentir-se desvalorizados pelo trabalho com o jogo, inclusive, buscam sua ressignificação social.

Cabe relatar que nossa hipótese, ao pesquisar os sentidos que os professores atribuem ao seu trabalho com o jogo na Educação Física escolar nas primeiras séries do ensino fundamental da rede estadual paulista, foi de que o professor concebe o trabalho a partir de perspectivas funcionalistas, deixando de percebê-lo como produto da cultura e como atividade que contém e reproduz as significações e valores sociais, e esta visão tem implicações na sua forma de trabalhar com o jogo em suas aulas.

5 Horário de Trabalho Pedagógico Coletivo 
Na Educação Física escolar costuma-se utilizar o jogo como simples atividade recreativa, sem levar em consideração seu caráter de transformação social, ou ainda, utiliza-se dele de forma descontextualizada, como um fazer por fazer, ou puramente para o alcance de aptidões físicas (SCHWARTZ, 1997). Conforme pontuado por Lima (2003), o jogo nas escolas de educação infantil e nas primeiras séries do ensino fundamental se manifesta diferentemente de quatro maneiras: como ausência e proibição da brincadeira; como recurso pedagógico; como atividade recreativa e como laissez-faire (fazer por fazer).

Nesse sentido, apesar dos sentidos expressos pelos professores irem ao encontro dessa ideia, esta visão é, ao mesmo tempo, reconstituída pelos professores de EF escolar e a forma como cada um trabalha com o jogo em sua prática pedagógica é constituída de forma única e particular. apropria-se de significações que são coletivas, mas, ao mesmo tempo, elabora e reelabora essas significações.

Os professores de outras áreas e a equipe gestora esperam que se reconheça o trabalho com o jogo dentro de um projeto de educação; no entanto, este processo educativo não está claro nem para os professores de Educação Física, já que para incluí-lo dentro de um projeto educacional pautam seu trabalho na leitura e na escrita, nas capacidades físicas e na exclusão do futebol.

Segundo Betti (2009); Bracht (1999) e Soares et al. (1992), a trajetória histórica da Educação Física foi constituída pautada por valores advindos das instituições médica, militar e esportiva, em que o trabalho com o jogo parece ter seguido os mesmos princípios, assim como os cursos de formação mantém "uma forte concepção biológica e a sua atenção no "saber fazer" (BENITES, SOUZA NETO E HUNGER, 2008, p. 347).

Estas significações estão muito presentes, ainda, no sentido subjetivo constituído pelos professores de Educação Física e afetam as relações que estes têm com os alunos, com os professores de outras áreas, com os pais e com a equipe gestora.

No momento em que a significação da Educação Física teve origem nessas instituições, exige-se do professor de Educação Física forma "perfeita", corpos esbeltos, sempre "em forma", excelente performance e além disso serem esportistas/atleta (GOMES, 1995).

Diante desses dados, podemos afirmar que a desvalorização do trabalho com o jogo pelos professores de outras áreas e pela equipe gestora expressa um processo histórico da Educação Física como componente curricular, fortemente marcada pelo "paradigma da aptidão física" ou "paradigma biológico". (BRACHT, 1999).

Na perspectiva sócio-histórica a concepção de homem-sociedade é pautada pela relação dialética, sobretudo, considerando o homem como ativo no seu meio. Não sendo só produto ou reprodução deste pode e é capaz de produzir o novo, de ressignificar sua prática pedagógica.

\section{Condições de trabalho com o jogo}

As condições adequadas de trabalho com o jogo, salário e formação também foram evidenciadas, afetando a maneira como o professor de Educação Física escolar trabalha com o jogo em suas aulas. 
Ao levantarmos dados referentes as condições de trabalho com o jogo pelos professores de Educação Física escolar, notamos que ele é desvalorizado na rede estadual paulista.

Os professores entrevistados não foram formados para atuar com a nova proposta curricular da Educação Física (FERNANDES, 2009) - somente os professores que foram classificados no concurso público é que participaram de curso de formação específica, denominado de "Curso de Formação Específica do Concurso Público para Provimento de Cargos de PEB II"; a maioria dos professores não foi preparada para trabalhar com a nova proposta. Há de se admitir que a formação precária em relação ao trabalho com o jogo e os péssimos salários, juntamente com as condições físicas e materiais, compõe a significação, e tem afetado a maneira como o professor de Educação Física atua na escola.

É possível notar que Isabel mostra-se bastante incomodada com a formação em serviço. "(...) eu trabalho há três anos e (...) nunca tive nenhum curso. (...) antes dele até pensar nas pessoas que estão começando, deveria pensar na gente. "

Ao referir-se a implementação da proposta curricular do Estado de São Paulo para as séries finais do ensino fundamental e ensino médio ressalta:

[...] quando chegou o caderninho ${ }^{6}$, a gente deveria ter se reunido. [...] É claro, cada um tem uma formação, cada um tem um jeito de trabalhar, tem ideia minha que alguém não concorda, tem ideias de pessoas que eu também não concordo. Mas que a gente deveria ter uma base, assim, para trabalha. Eu não sou contra o caderninho, eu achei que ficou sistematizado, mas a gente não teve formação nenhuma.

Júlio Cesar também evidencia a falta de formação para desenvolver os conteúdos implementados no currículo para as séries iniciais do ensino fundamental.

[...] uma coisa que pega muito para a área da Educação Física é a parte de formação. Que nem, o estado de São Paulo implementou uma mudança muito grande em relação a Educação Física, uma estruturação muito grande. Mas ao mesmo tempo, faltou uma formação melhor para os nossos professores. Então, entrou com uma proposta nova, uma metodologia nova de trabalho, e nós não fomos preparados para isso.

O fato é que não existe proposta específica implementada pela Secretaria de Educação do Estado de São Paulo (SEE/SP), até o momento do desenvolvimento desta pesquisa, para as primeiras séries do ensino fundamental, e isso é do conhecimento de todos os professores entrevistados. No entanto, cada um adequa seu trabalho com o jogo de uma maneira peculiar e particular.

É possível notar que apenas Augusto mostra-se insatisfeito com o salário, sem, contudo, reconhecer como fator de desvalorização do seu trabalho.

6 O caderno é um material distribuído para as escolas a fim de materializar a Proposta Curricular do Estado de São Paulo/SP e sistematizar os conteúdos a serem trabalhos pelos professores de $5^{\mathrm{a}} \mathrm{sé}$ iie $/ 6^{\circ}$ ano a $8^{\mathrm{a}}$ série $/ 9^{\circ}$ ano do Ensino Fundamental e ensino médio. São compostos por 76 cadernos (do professor e do aluno) organizados por bimestre, série/ano e disciplina. 
Salário é meio (...) [...] hoje a Educação Física já mudou um pouco exatamente por isso. Hoje em dia você já (...) ela já te oferece um campo onde você pode ser um empresário do ramo da Educação Física. Você pode ser um 'personal trainer', você pode estar atuando em outras áreas. O magistério era a única área. Você fazia uma coisa para o magistério, depois você ia trabalhar com esportes ou outra coisa parecida. Hoje em dia não. Hoje em dia existe uma área de magistério e existe uma área para outros segmentos da Educação Física. Ela é rentável hoje dependendo de como você trabalha.

Júlio César, que acumula cargos na rede pública e na rede privada, expressa que na rede estadual sente necessidade de uma automotivação para desenvolver seu trabalho com o jogo.

[...] atualmente eu consigo exigir mais dos meus alunos daqui do estado que da rede particular. Primeiro por causa da estrutura de quadra, espaço, a quantidade de alunos, então assim, eu consigo dar umas aulas mais elaboradas aqui do que lá. Assim, em relação as aulas de EF no geral. Eu consigo ir muito mais além aqui do que lá. Mas, acho que principalmente, isso depende muito do nosso compromisso, a gente acaba tendo uma... precisa de ter uma automotivação muito grande, porque, assim, a exigência aqui é menor. Então, assim, eu sei por mais que eu posso muito bem fazer um excelente trabalho bom ou fazer um trabalho nivelado por baixo que não vai acrescentar muita coisa. É diferente da escola particular, que de repente se eu começar a fazer um trabalho que ficar muito aquém, começa a vir as reclamações, posso ser principalmente mandado embora.

Joana, que também acumula cargos, atua na rede pública e na universidade privada. Ela alega que o seu trabalho com o jogo no ensino superior fundamenta o seu trabalho com o jogo na rede estadual com crianças das primeiras séries do ensino fundamental e vice-versa, permitindo conciliar os dois com sua "vida pessoal"; entretanto, considera o espaço como forte limitador do seu trabalho com o jogo na rede estadual.

Já Isabel não encontra dificuldades em relação aos materiais e as condições físicas, mas destaca a dificuldade em trabalhar com o jogo quando é a primeira vez que vai ensinar o jogo aos alunos.

Eu tenho um espaço físico bom, eu tenho uma quadra grande, coberta. O espaço físico é bom. Eu tenho um material bom até. Eu consigo trabalhar com aquele material e tal. A dificuldade é sempre quando você vai ensinar pela primeira vez. Então, você tem que ensinar, explicar, fazer.

Augusto, por sua vez, destaca a diversidade cultural presente entre os alunos como um dificultador no desenvolvimento do seu trabalho com o jogo.

[...] o preconceito dentro de uma aula, ele existe muito no competitivo. Vou te dar um exemplo: os alunos já escolheram o time. Então, cada dia, se eu vou trabalhar o jogo competitivo ou semi-cooperativo, todo mundo quer escolher. Então, eu acompanho a ordem alfabética ali da caderneta. Então, fulano, fulano. Aí de repente, 


\begin{abstract}
a pessoa que está escolhendo, ele é um menino assim que não tem muito a ver com o jogo e tudo mais. Aí o outro fala assim: Eu não! Sabe aquela coisa? Ou, vai um gordinho. Ah, logo ele. Sabe? O preconceito na verdade não está no aluno, o preconceito está na gente e a gente enquanto adulto está transferindo esse preconceito para o aluno. [...] É um ciclo e a gente tem que filtrar isso de alguma maneira, trabalhar de alguma maneira.
\end{abstract}

Com base nas falas dos professores entrevistados, é possível afirmar que eles não reconhecem que o baixo salário compõe e faz parte da desvalorização do seu trabalho na rede estadual paulista, juntamente com as condições físicas, materiais e as questões sócio-histórica e culturais Este conjunto de significações dificulta e, portanto, impede a ressignificação do jogo, na medida em que impossibilita o desenvolvimento de um projeto crítico, mais amplo e coletivo de trabalho.

Este fato vai de encontro ao alertado por Krug (2008), o "mal-estar docente", expresso nas limitadas condições de trabalho e na precária remuneração que afetam a qualidade do trabalho dos professores de Educação física. Corroborando esta ideia, Gatti (2000) destaca que a desvalorização/valorização social da área profissional afeta a maneira como o professor estrutura sua carreira, assim como dificulta que o professor reconheça que sua carreira possa ser bem remunerada.

Referindo-se à Educação Física escolar, Krug (2008) questiona: "Vale a pena ser professor de Educação Física escolar? ". Sobre isso, além da falta de um plano de carreira para os profissionais da rede estadual paulista, nota-se que a SEE/SP responsabiliza os professores pelo fracasso dos alunos, no momento em que promove o aumento do salário, com base na prova de promoção por mérito ${ }^{7}$ e coloca a formação em serviço on-line como avaliadora da "competência técnica" do professor, deixando para segundo plano as discussões sociais, políticas e econômicas. É possível notar que os professores utilizam a formação oferecida pela SEE/SP para ressignificar o seu trabalho com o jogo na rede estadual paulista nas primeiras séries do ensino fundamental.

Nesse sentido, ao mesmo tempo em que a formação pode significar um novo sentido do cooperar/competir, para eles pode também tornar o seu trabalho com o jogo mais eficiente, tornando-os competentes e merecedores do aumento de salário. Este sentimento é expresso por Júlio César ao relatar que os "novos professores vão entrar muito mais preparados e têm condições de desenvolver um trabalho muito mais eficiente".

No entanto, ele mesmo não participou do curso de formação on-line oferecido somente aos professores que foram classificados no concurso. Incomodado com a falta de preparo, o professor Júlio César afirma: "eu dei a sorte de ter uma formação muito boa".

Para Fernandes (2009), a adesão à proposta curricular do Estado de São Paulo e a preocupação com a formação é, para os professores de Educação Física escolar, um motivo de valorização social da área. Entretanto, destaca que os professores mudaram algo quando foram fazer uso da orientação vinda da SEE/SP. O modo como todos os professo-

7 Lei Complementar no 1.097, de 27 de outubro de 2009. Institui o sistema de promoção para os integrantes do Quadro do Magistério da Secretaria da Educação e dá outras providências. 
res entrevistados estabeleceram relação com a proposta não foi o de meros executores e reprodutores, já que a aplicação não se deu de maneira mecânica e esquemática. Mesmo cada um alegando os seus motivos, todos os professores mudaram alguma coisa. Embora se deva enfatizar que a proposta foi implantada para orientar a prática pedagógica dos professores que atuavam nas séries finais do ensino fundamental e ensino médio, no entanto, eles a utilizavam como um "norte" para o ensino da Educação Física nas séries iniciais (FERNANDES, 2009).

Por fim, é possível notar a desvalorização, objetivada na formação em serviço, no plano de carreira, nas condições de trabalho, na estrutura física e material, nas dificuldades apresentadas pelos alunos, no entendimento que se tem da Educação Física, dentre outros aspectos apontados por esta pesquisa, são considerados como de menor importância nos sentidos constituídos pelos professores de Educação Física no trabalho com o jogo. Os maiores incômodos dos professores de Educação Física encontram-se centrados no objetivo a ser alcançado no trabalho com o jogo e no "como" organizar tal conteúdo, ao invés de questionar o "por quê" tal conhecimento deve ser ensinado.

\section{CONSIDERAÇÕES FINAIS}

Só os homens podem destruir o que eles mesmos criaram para abrir caminho a uma nova criação. Só eles fazem sua própria história, ainda que, como adverte Marx, em determinadas condições. (...) Assim, pois, a história só existe como história feita pelos homens, e estes só existem produzindo uma nova realidade com sua práxis produtiva e produzindo-se a si mesmos num processo que não tem fim, ou seja, os homens transformam e se transformam a si mesmos, e essa história de suas transformações é propriamente sua verdadeira história. Vázquez (1968)

O objetivo deste estudo foi compreender a dimensão subjetiva constituída sobre o trabalho com o jogo pelos professores de Educação Física escolar que atuam nas primeiras séries do ensino fundamental, da rede estadual paulista de uma diretoria de ensino, localizada no interior do estado de São Paulo/SP. De acordo com Vázquez (1968), a história é dinâmica e o homem é sujeito de sua própria história; cria, recria, dicotomiza e contradiz, por meio das relações que estabelece com as pessoas com quem convive. Diante deste objetivo, este estudo permitiu compreender, à luz de uma perspectiva crítica de educação, as significações constituídas sobre o jogo com a hipótese de que elas interferem na forma como o professor atua em suas aulas.

Podemos afirmar, a título de conclusão, que os dados revelam uma visão funcionalista de jogo, em que deixa de percebê-lo como produto da cultura e como atividade que contém e reproduz as significações e valores sociais, entretanto, buscam sua ressignificação.As significações evidenciadas nas falas pelos nossos sujeitos, professores de Educação Física escolar da rede estadual paulista, expressam um processo histórico. Atuam em uma instituição, cujos valores se originaram em instituições: médicas, militares e esportivas; 
em que a técnica e a tática no trabalho com o jogo foram "necessárias" à sociedade e cujos valores somente começaram a ser questionados pela área no início dos anos 80 . A Educação Física escolar, e com ela o jogo, vive em um processo de busca pela sua valorização, o que significa um confronto infindável entre o "velho" e o "novo", que orienta a prática pedagógica, por meio de suas "novas" leis, referenciais e princípios, mas que, apesar do aparato-legal, os professores tentam, muitas vezes solitariamente, ressignificar, transformando sua prática pedagógica de uma maneira única e particular. Sem respaldo ou apoio em um projeto coletivo, ficam isolados e suas práticas inovadoras tendem ao fracasso ou à pequenez das experiências isoladas.

Não queremos apregoar o relativismo, ao afirmar que cada professor de Educação Física escolar constitui seu trabalho com o jogo de maneira única e particular ou deixando de considerar o sentido que acreditamos que o trabalho com o jogo deve constituir numa formação de professores de Educação Física. Sabemos que o aparato legal que orienta a prática pedagógica do professor de Educação Física compõe a significação coletiva sobre o trabalho com o jogo e faz parte do sentido que cada professor de Educação Física constitui sobre este, mas o professor elabora, reelabora, recria e transforma essas significações.

Nesse sentido, estamos dando vida, vez e voz aos sujeitos e reforçando a ideia de que cada um faz parte da construção da história e de que podemos mudá-la. "Somos responsáveis pelo mundo que temos e podemos querer que seja diferente. " (GONÇALVES e BOCK, 2009, p. 154).

\section{REFERÊNCIAS}

AGUIAR, Wanda Maria Junqueira; OZELLA, Sérgio. Núcleos de significação como instrumento para a apreensão da constituição dos sentidos. Psicologia ciência e profissão, vol. 26, n. 2, p. 222-245, jun. 2006.

. Apreensão dos sentidos: aprimorando a proposta dos núcleos de significação.

Revista Brasileira de Estudos Pedagógicas, Brasília, v. 94, n. 236, p. 299-322, jan./ abr. 2013.

BETTI, Mauro. Educação Física e sociedade: a Educação Física na escola brasileira. 2. ed. São Paulo: Hucitec, 2009.

BOCK, Ana Mercês Bahia. Aventuras do barão de Münchhausen na psicologia. São Paulo: EDUC: Cortez Editora, 1999.

BRACHT, Valter. A criança que pratica esporte respeita as regras do jogo...capitalista. Revista Brasileira de Ciências do Esporte, v. 7, n. 2, p. 62-68, 1986.

A constituição das teorias pedagógicas da educação física. Cadernos Cedes, Campinas, v. 19, n. 48, p. 69-88, ago. 1999.

CAPARROZ, Francisco Eduardo. Entre a Educação Física na escola e a Educação Física

da escola: a Educação Física como componente curricular. 3. ed. Campinas: Autores Associados, 2007. 
ELKONIN, D.B. Psicologia do jogo. São Paulo: Martins Fontes, 1998.

FERNANDES, Anoel. A proposta pedagógica para a educação física escolar nas séries iniciais da rede pública estadual paulista: as manifestações dos professores. Dissertação (Mestrado em Educação), Pontifícia Universidade Católica de São Paulo - PUC/SP, 2009.

FIGUEIREDO, Zenólia Christina et al. Educação física, ser professor e profissão docente em questão. Pensar a prática, v. 11, n. 2, p. 209-218, maio/agosto, 2008.

GATTI, Bernardete Angelina. Formação de professores e carreira: problemas e movimentos de renovação. 2. ed. Campinas: Autores Associados, 2000.

GOMES, Christiane Luce. O uso do Corpo pelo jogo de poder na Educação Física. Dissertação (Mestrado em EF) - Universidade de Minas Gerais, 1995.

GONÇALVES, Maria da Graça Marchina e BOCK, Ana Mercês Bahia. A dimensão subjetiva dos fenômenos sociais. In: BOCK, Ana Mercês Bahia; GONÇALVES, Maria da Graça Marchina (Orgs.). A dimensão subjetiva da realidade: uma leitura sócio-histórica. São Paulo: Cortez, 2009.

KRUG, Hugo Norberto. Vale a pena ser professor ... de Educação Física escolar?. Lecturas: Educación Física y Deportes. Revista digital, v. 13, n. 122, Buenos Aires, 2008.

LIMA, José Milton. A importância da brincadeira para o desenvolvimento das múltiplas inteligências da criança. In: MORTATTI, M. R. L. Atuação de professores: propostas para ação reflexiva no ensino fundamental. Araraquara: JM Editora, 2003. p. 63-87.

LÜDORF, Silvia Maria Agatti. A prática pedagógica do professor de educação física e o corpo de seus alunos: um estudo com professores universitários. Pensar a prática, v. 8, n. 2, p. 243-255, jul. /dez. 2005.

MUNIZ, Neyse e FONSECA, Ingrid. O brincar na educação física escolar: em busca da valorização das diferentes perspectivas. Revista Brasileira Ciências do Esporte, Campinas, v. 21, n. 2 e 3, janeiro-maio. 2000.

NEIRA, Marcos Garcia; NUNES, Mário Luiz Ferrari. Pedagogia da cultura corporal: crítica e alternativas. 2. ed. São Paulo: Phorte, 2008.

NEIRA, Marcos Garcia. Em defesa do jogo como conteúdo cultural do currículo da educação física. Revista Mackenzie de Educação Física e Esporte. São Paulo/SP, v. 8, n. 2, 2009, p. 24-41.

REY, Fernando Luiz González. Pesquisa qualitativa e subjetividade: os processos de construção da informação. São Paulo: Pioneira Thomson Learning, 2005.

. O social na psicologia e a psicologia social: a emergência do sujeito. Petrópolis: RJ: Vozes, 2009.

SANTOS, Fernanda do Nascimento Lopes. As diferentes formas de utilização do jogo identificadas a partir da produção teórica da educação física: o que está em jogo?, 2004. Dissertação (Mestrado em Educação Física) - Universidade Gama Filho, 2004. SCHWARTZ, G. M. Atividades lúdicas e educação física: possível dissonância?. 1997. Tese (Doutorado em Psicologia) - Universidade de São Paulo, São Paulo/SP, 1997. SOARES, Carmen Lúcia et al. Metodologia da Educação Física. São Paulo: Cortez, 1992. 
STUMPF, Jussara Marchioro. O jogo nos dizeres e fazeres dos professores de educação física que atuam nas séries iniciais do ensino fundamental. Dissertação (Mestrado em Educação Física) - Universidade Federal do Rio Grande do Sul, 2000. VÁZQUEZ, Adolfo Sanchez. Filosofia da práxis. Rio de Janeiro: Paz e Terra, 1968.

Recebido em: agosto/2016 Aprovado em: agosto/2017 